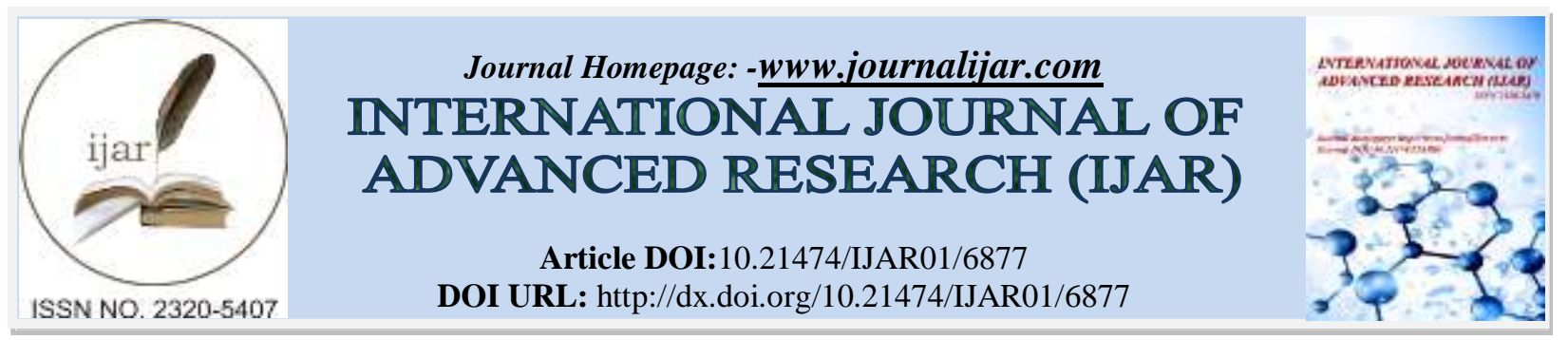

RESEARCH ARTICLE

\title{
ACADEMIC COUNSELLING SERVICES IN INDIRA GANDHI NATIONAL OPEN UNIVERSITY (IGNOU).
}

Dr. Pravat Kumar Jena.

Assistant Regional Director, IGNOU Regional Centre, C-1, Institutional Area, Bhubaneswa-751013.

\section{Manuscript Info}

Manuscript History

Received: 07 February 2018

Final Accepted: 09 March 2018

Published: April 2018

\section{Keywords:-}

Distance education, IGNOU system, academic counselling, teaching learning strategy, perception of learners and counsellors on counselling.

\begin{abstract}
Academic counselling is an important activity of learner support services offered by Open and Distance Learning (ODL) system. It is the key to the learners' success in ODL system. The geographical separation of the teachers and learners along with socio-psychological constraints i.e. language, culture, motivation, inadequate skill, anxiety etc., affects the distance learners in completing the courses successfully. The counselling sessions also offer the students an opportunity to interact with their peers. The counsellors perform various roles, such as facilitating learners about the subject matter content, assessing assignments, providing motivation and encouragement and supervising research papers/project works. Since counselling is an important component of distance education, it is necessary to understand the concept.

The Indira Gandhi National Open University (IGNOU) provides highly integrated learner support services through the network of study centers, regional centers and the headquarters. One of the major objectives of IGNOU has been to provide opportunities of higher education to a large segment of population and to develop new programme for adult learners for whom formal education system was quite difficult or impossible.
\end{abstract}

Copy Right, IJAR, 2018,. All rights reserved.

\section{Introduction:-}

Providing education at a distance is the simplest definition of distance education. Today, distance education, elearning, virtual education, or whatever name we prefer is basically a method of teaching where the student and instructor are separated by time or space, or both. The ODL has become an integral part of higher education globally. In fact, the major contributory factors behind the emergence of the ODL system were the universal demand for education, thirst for knowledge and the failure of the mainstream education system in catering to the increasing popular demand for higher education. Distance education is the most economical form of higher education. The ODL system has proved to be the alternative to the conventional system as it has not only proved cost effective but also has the right potential to reach out to the large segment of the unreached, marginalized and the needy. The success of this new mode of education largely depends on the effective student support system.

The foundations of Distance Education can be traced back to the late 1800's. One of the first forms of distance education was correspondence course study. Sir Issac Pittman founded Sir Isaac Pitman's Correspondence Colleges in England in the mid 1840s. Correspondence courses took advantage of the then new rural free delivery of mail to deliver course material to students. Students worked independently on course material and interaction between 
faculty and students was limited to one-way communications. Within a few decades, correspondence courses were developed in Germany, Canada, Australia, the Soviet Union, Japan, and the United States (Matthews, 1999, P. Satyanarayana \& C Sesharatnam, 2000). The establishment of the British Open University (1969) marked a significant development in the delivery of distance education by offering a mixed-media approach to distance learning technologies. Learning materials (text, audio \& visuals) were sent to students by mail and supplemented by broadcast radio and television (Matthews, 1999). Distance education has always been an important pillar for developing the literacy rate of any country. This mode of education make it easy to reach far flung areas and to the section of society, which is somehow, not able to avail the conventional techniques of education.

Now-a-days, the distance mode of education is becoming more popular than the conventional education. Distance learning is an excellent method of adult learners to possess the desired higher degree of qualification. The structure of distance learning gives adults the greatest possible control over the time, place and pace of education. Loss of student motivation due to the lack of face-to-face contact with teachers and peers, potentially prohibitive startup costs, and lack of faculty support are all hurdles to successful distance learning system. Distance education is much more flexible and student centered in approach. By allowing students to learn in more convenient locations, and often at more convenient times, distance education opens educational opportunity to previously un-reached learners. It also enables students to extend the period of their education from a limited number of schooling years to a lifelong learning process. The distance mode of education plays an important role in meeting the needs of such persons who are in great demand of education but can't complete their education from the formal or regular system of education.

In Open and Distance Learning (ODL) system, academic counselling is an important activity of learner support services which plays the key role in the learners' success. The dictionary meaning of counselling is the provision of professional assistance and guidance in resolving personal or psychological problems. Counselling is the process of assisting and guiding clients, especially by a trained person on a professional basis, to resolve especially personal, social, or psychological problems and difficulties. It is the process that occurs when a client and counsellor set aside time in order to explore difficulties which may include the stressful or emotional feelings of the client. Effective counselling reduces confusion, allowing the client to make effective decisions leading to positive changes in their attitude and/or behaviour. Effective counselling is not advice-giving and is not acting on someone else's behalf (these are more than the roles of a life coach). The ultimate aim of counselling is to enable the client to make their own choices, reach their own decisions and to act upon them accordingly. Counselling is very important aspect in teaching learning process of distance education system. Students counselling begins with the pre-admission period, continues through the duration of the programme and it is helpful even after the programme is completed.

\section{Objectives of the study:-}

Counselling is very important aspect in teaching learning process of distance education system. The objective of this study is to analyze and understand the types of counselling services provided by IGNOU and to suggest measures to improve quality of counselling services for making the service interesting for the learners.

\section{Methodology:-}

Some books, journals and e-contents related to counselling services in distance education and distant learners are studied to find out the problems associated with counselling services of distance education system and its target group. Various problems faced by distance learners regarding counselling services were discussed and suggestive solutions for the betterment of the counselling services are suggested. The data on counselling services are collected from various research papers, ODL institution profiles and from study centres under a Regional centres of IGNOU. The collected data are analyzed to study merits and demerits of counselling services and proposed better methods of counselling to make it effective for the learners of ODL system.

\section{Implication of the study:-}

The significance of this study is:

1. Study of the details of Counselling services provided by the IGNOU.

2. Counseling strategies of IGNOU.

3. Study on different modes/media used for counselling.

4. Perception of academic counsellors towards academic counselling sessions of IGNOU.

5. Perception of learners on academic Counselling of IGNOU. 


\section{Indira Gandhi National Open University System:-}

Indira Gandhi national Open University (IGNOU) was established by an Act of Parliament in 1985. It is an apex body for open and distance learning (ODL) system in India. The university has nation-wide operation having headquartered at New Delhi, 67 Regional Centres with about 3000 Study Centres throughout India. The study centres are the academic contact points for distance learners and the university engages around 33,212 academic counsellors for providing learner support services to the heterogeneous distance learners (IGNOU profile, 2017). In IGNOU, the academic counsellors are mostly drawn from the conventional system of higher education and the exposure of the counsellors towards ODL system is minimal. However, the academic counsellors are the pivotal link between the ODL institution and isolated distance learners in IGNOU. Their role in handling face-to-face academic counselling sessions at the study centre is very important. Though, periodical training is given to them by IGNOU, it is a difficult task to train such a massive number of counsellors across the country. For maintaining quality in academic counselling, the accumulation of multi-dimensional skills, attributes and information is essential on the part of the cunsellor in ODL system. The student support services at IGNOU are managed through the Regional Services Division (RSD) with the support of Regional Centers (RCs) and Study Centers (SCs). The RCs and SCs provide facilities in terms of general and programme specific information, student enrolment, academic support relating to counselling, assignment evaluation, conducting examinations etc.

\section{Functions of Regional Services Division:-}

The Regional Services Division (RSD) was established in February 1986 to operationalise the Regional Centres, Study Centres and Student Support Services of the University across the length and breadth of the country.

The responsibilities and functions assigned to the RSD are as follows:

1. Develop policies, systems and procedures in respect of establishment and management of Regional Centres and Study Centres.

2. Organise and administer the national network of Regional Centres and Study Centres.

3. Negotiate with Government Departments, educational institutions, other organisations including voluntary organisations for establishment of new Regional Centres and Study Centres.

4. Identify and appoint suitable persons as Academic Counsellors for counselling, practical and evaluation of assignments.

5. Organise orientation programmes for part-time functionaries of Study Centres.

6. Funding and expenditure control of Regional Centres and Study Centres.

\section{Functions of Regional Centres:-}

The IGNOU Act defines the "Regional Centre" as a centre established or maintained by the University for the purpose of coordinating and supervising the work of Study Centres in the region and for performing such functions as may be confirmed by the Board of Management of the University. Regional Centre is considered as face of the University for all its practical purposes. Regional Centre maintains effective link between the different Schools and Divisions of the University and Learners Support Centres, between IGNOU and respective State Governments and between IGNOU and the general stakeholders. Regional Centres, the sub-office of the University for all practical purposes, are also intended to act as resource centres of the University in respective regions. Regional Centres are centres for training coordinators/counsellors/other functionaries and would provide a venue for the students and the academic counsellors to express their responses with reference to a particular subject. Regional Centre explores the avenues and opportunities to establish study centres in institutions of repute under its jurisdiction so that the students may get full benefit and advantage of educational opportunities through open and distances learning system at their door steps.

Various academic activities undertaken by regional centers are as follows:

1. Student admission and maintenance of their records;

2. Orientation programme for the coordinators, counsellors and other functionaries;

3. Induction programme for the new students;

4. Identification of institutions for setting up of study centres;

5. Appointment of counsellors, staff etc;

6. Development of region specific academic programmes;

7. Conduct of term end examinations;

8. Organizing seminars and workshops, maintenance of support services etc;

9. Monitoring of study centre regarding counselling, assignment evaluation, examination; 


\section{Functions of Study Centres:-}

Study centers are the main providers of support services in the distance education system which are housed in existing educational institutions of higher learning such as universities and colleges; non-governmental organizations etc. To fulfil the requirements of the learners, various types of study centers are set up by IGNOU, such as Regular Study Centers, Programme Study Centers, Special Study Centers, Recognized Study Centers, Work Centers and Partner Institutions. The study centers are headed by a Coordinator or Program In-Charge who is assisted by Assistant Coordinators or Assistants with other supporting staff. The major activities performed at the study centers are student guidance and counselling (both theory and practical), use of the audio, video and teleconferencing facilities, library facility, assignment evaluation, liaison with regional centre and headquarters, conducting term end theory and practical examination and entrance examination.

\section{Other responsibilities of Study Centre of IGNOU are:-}

1. To guide distance learners in the choice and management of peer groups for the purpose of tutorial and other instructional facilitation.

2. To devise, develop and manage student database and constantly monitor all counselling needs of students for the purpose of providing effective guidance and counselling services.

3. To liaise with Regional centre and with IGNOU headquarters regarding counselling matters relating to examination and assignments.

4. To provide follow-up services i.e. the counsellor remains in constant touch with the student in order to ensure that he/she does not drop out from the academic pursuit

5. To provide guidance in the choice of suitable techniques and encourage development of a sustainable study habit.

6. To provide guidance services on change of programmes, suspension and deferment of admission.

7. To receive assignments and get them evaluated from the concerned counsellors and arrange to send the feedback to the students with report and award list to RC.

8. To identify course-specific academic counsellors and coordinate the work of all the individual counsellors.

9. To prepare schedules of Counselling / Practicals / Clinical Sessions in consultation with Head of the Host Institution.

10. To oversee conduct of Counselling / Practicals / Clinical sessions and maintain a record of attendance.

11. To arrange periodic meetings with the counsellors and students to review progress of the programme

\section{Different stages of counselling used in IGNOU:-}

Different types of support services are required in distance education by the learners at various stages like pre-entry stage, during the course stage, at the examination stage and at the post-study stage.

\section{Pre-admission counseling:-}

The type of support required at pre-entry stage would include:

1. Guidance about the types of programmes and courses available in the distance education institute.

2. Pre-admission counseling with regard to selection of courses.

3. Information regarding the instructional system, entry requirements, fee structure, duration of the programme of study.

4. Advice regarding fee reimbursement and fee concession.

\section{Counselling during the course:-}

The type of support services needed during the course are as below:

1. Introduction into the instructional system of the institution.

2. Distribution of self-learning materials, assignments etc.

3. Information about TV progarmmes, radio broadcasts, teleconferencing sessions etc.

4. Provision of library services.

5. Organisation of practical at science labs, computer labs, industry etc.

6. Organisation of assignment evaluation and providing feedback through tutor comments.

7. Development of study skills and structuring the students learning skills.

8. Provision of counseling and tutoring services.

9. Guidance before examination.

10. Communication of results of assessments.

11. Provision of relevant accurate and unbiased information. 


\section{Post completion counselling:-}

The type of support services required at post-completion counselling stage would include:

1. Communication regarding final results/grades/awards, convocation etc.

2. Advice regarding career advancement/job opportunities/future prospects.

3. Obtaining feedback on the programme and services provided.

\section{Academic Counselling Services of IGNOU:-}

There are various modes used for academic counselling in IGNOU. Distance learning takes place through both as an individual's interaction with the Self Learning Materials and social interaction with peers/tutors (STRIDE, IGNOU, MDE-413, 2012). All these communication takes place through various media. Some of the media used in IGNOU are as follows:

1. Counselling through Face to face mode

2. Counselling through Assignments

3. Counselling through Technology

\section{Counselling through Face to Face mode:-}

Many distance learners may find it difficult to handle the self-learning materials with their various access devices, activities and assignments. These would require knowledge of study skills which can be provided through human support. IGNOU is providing face to face counseling through local support centres or study centres which are the best places to provide face-to-face counseling sessions. The distance learners are informed well in advance about the specific period and place where the face-to-face sessions are to be held. In IGNOU, learners are getting immediate clarification of their doubts through face to face counseling mode.

\section{Counselling through Assignments:-}

Assignments are an important vehicle for students in obtaining feedback from and establishing a dialogue with their teachers. In distance education system, continuous assessment is done through assignments. For each course, the IGNOU learners have to submit the responses of the assignment questions given by the University. Then the assignment responses are evaluated by an academic counsellor, who provides grades/marks with positive feedback comments. The feedback comments of the evaluator on the assignment responses are very important as it is expected to improve the performance of the learner. Therefore, the evaluator should write good feedback with sufficient and clearly explained positive comments to encourage and motivate the learners.

\section{Counselling through Technology:-}

In IGNOU, multiple technologies such as radio, television, telephone, mobile technology, computer and internet make a critical difference to everything we do. Each technology has its own advantages and disadvantages. But largely, these technologies are found very much useful in counselling. With the help of telephones and mobile phones, counselling is provided on one-to-one basis and to a group of learners through teleconferencing. Similarly, counselling is also being provided through interactive audio-video programmes. Instead of face-to-face counseling, different audio-video programmes on CD ROMs and Audio Cassettes are also used according to the needs of the learners. In IGNOU, counselling is provided to a maximum number of learners at a time through live interactive programmes. Now-a-days internet and e-mail facilities make our work much easier. Counsellors do use email facilities to provide one-to-one as well as group counseling effectively. Online counseling is provided to a large number of learners at a time all across the globe with the use of internet. In this way, technologies are being used effectively for both academic and non academic counseling.

IGNOU is using fixed time radio broadcasts and television broadcasts which are also available on the National All India Radio Channels and on the National Doordarshan channels. These are aired and available to the public. Using this media, counselling is provided to a maximum number of learners at a time through live interactive programmes. IGNOU is also using teleconferencing including one-way video and two-way audio teleconference system via satellite mode. This system is available at all the Regional Centres and some study centres of IGNOU. Learners can visit the receiving centres and interact with the experts who are based in the studio at the Headquarters. These sessions are found to be very much useful in professional programmes like post B.Sc (Nursing), Post Graduate Diploma in Higher Education and other Medical programmes where the learners across the country get an opportunity to learn from experts who would otherwise be inaccessible to them at far off places. 


\section{Teaching Learning Strategy of IGNOU:-}

IGNOU is offering different levels of programmes like Certificate, Diploma, Bachelors and Masters Degree. The number of programmes offered at these levels is around 228. The university decides the study hours or workload of learners' based upon the number of credits. For example, a learner has to work for 16 credits $(1$ credit $=30$ study hours) for six months certificate programmes whereas the workload for study is 32 credits for programmes of one year duration. In case of programmes of more than one year duration, the study work load is in multiples of 32 credits (i.e., $3 \times 32=96$ for Bachelors' degree programme.) Out of the total study hours in terms of credits to be completed, $10 \%$ of the studies hours are covered through the face-to face academic counselling at the study centres of IGNOU. The remaining $90 \%$ of the study hours are to be undertaken by learners through self-study with the help of Self-Learning Materials (SLM), writing assignments, getting multimedia support etc. Even though, the counselling sessions allotted are very minimal, only during the counselling sessions the learners come into direct contact with the academic counsellor and their peer groups (S. Kishore, 2014). The academic counselling sessions are very important for a distance learner.

The most important aspect in the teaching learning process is the quality of self-learning materials. Self-learning materials could be in the form of printed materials, CD-ROMs, audio, video, DVDs, Web based materials, etc. Being a flexible system generally there is a minimum and maximum period during which a learner is supposed to complete the programme of study. It is desirable to have programmes quantified in terms of credits. A credit is the study input required by a learner to complete a particular programme. One credit is equal to 30 study hours. Credits are assigned to programmes on the basis of average study hours required to successfully complete the prescribed course contents to meet the academic competency required. The credits also determine the volume of course content, number of counselling sessions and assignments which are also given in the table below (DEC, IGNOU, Handbook 2009):

Table:-

\begin{tabular}{|l|c|c|c|c|c|}
\hline $\begin{array}{c}\text { Norms for delivery of courses } \\
\text { through distance mode credit } \\
\text { value of the course }\end{array}$ & $\begin{array}{c}\text { Study input } \\
\text { (hours) }\end{array}$ & $\begin{array}{c}\text { Size of } \\
\text { SLMs } \\
\text { (units) }\end{array}$ & $\begin{array}{c}\text { Counselling } \\
\text { hours Theory } \\
\text { (hours) }\end{array}$ & $\begin{array}{c}\text { Practical } \\
\text { Sessions } \\
\text { (hours) }\end{array}$ & $\begin{array}{c}\text { No. of } \\
\text { Assignments }\end{array}$ \\
\hline 2 Credits & 60 & $6-8$ & 6 & 60 & 1 \\
\hline 4 credits & 120 & $14-16$ & 12 & 120 & 2 \\
\hline 6 credits & 180 & $20-24$ & 18 & 180 & 2 \\
\hline 8 credits & 240 & $30-34$ & 24 & 240 & 3 \\
\hline
\end{tabular}

As per the data collected from different study centres coming under jurisdiction of IGNOU Regional Centre, Bhubaneswar, it was noticed that "clarifying doubts", "gaining deeper insights into the subject" and "breaking isolation" appear to be the main responses which necessitate counselling class sessions. The academic counsellors and learners have also put different views on academic counselling services provided by IGNOU as pointed below.

\section{Perception of Academic Counsellors towards Academic Counselling Sessions of IGNOU:-}

Opinions of different academic counsellors of IGNOU engaged at different study centres, are analyzed and the perception of the academic counsellors towards counselling sessions of IGNOU are summarized in the following ways.

1. The learners do not attend counselling sessions maybe due to paucity of time or on account of other commitments.

2. They may not find the Counselling Sessions useful and interesting.

3. The learner feels that he/she does not need counselling.

4. Learners are tongue tied as they are not habituated to attend counselling sessions or are diffident to discuss their problems in front of others.

5. The counsellors being drawn from conventional system are unable to overcome biases and easily reverts to the lecture method, instead of initiating a good dialogue amongst the learners present.

6. Sometimes it is difficult to handle the learners from heterogeneous backgrounds.

7. Some learners do not submit assignment responses on time and do not collect the assignment responses detailed comments for better performance.

8. Lack of regular orientation programmes for the counsellors at various study centres in a given region.

9. Lack of adequate advance information about counselling schedules to the learners and adherence to the schedules. 
10. Review and renew of all appointments of counsellors, is not done systematically and regularly.

\section{Perception of Learners on Academic Counselling of IGNOU:-}

The opinions of different IGNOU learners admitted for different programmes engaged at different study centres, are also analyzed and the learners opined that counselling sessions help the distance learners in the following ways.

1. Counselling sessions help to break the sense of isolation of the learner. During counselling sessions, the learner is able to come in contact with other learners whom he does not meet often.

2. The first induction meeting as a counselling session is an icebreaker, as the learner is made familiar with the study centre set up, library, multimedia facilities, staff and academic counsellors.

3. Doubts and queries are answered properly by the functionaries. Some of them opined that tips are offered on how to study as an independent learner in the distance learning mode.

4. Counselling sessions although beneficial are not made compulsory.

5. Attendance at counselling sessions helps the learner to overcome obstacles, both of academic and non-academic nature.

6. Some counsellors do not evaluate assignments on time and return them with no detailed comments for better performance.

7. Low attendance at the sessions leads to suspension of regular counselling sessions because the number of learners attending and present is less than the prescribed number of learners.

8. The learner, who wants support and is present, has to suffer because of the other learners who do not feel the need for counselling or remain absent.

9. Counselling is conducted properly for the compulsory courses where the number of enrolled learners is quite large whereas learners of elective/specialization courses get divided into lesser numbers resulting few counselling classes.

10. The need for counselling is felt much more for the specialization courses but often does not take place.

\section{Recommendations/Suggestions:-}

Following few recommendations/suggestions may be considered for betterment of IGNOU counselling services.

1. For student counsellor to be effective, he/she must be approachable, competent in relationship building, empathetic, warm, have positive regard, genuine, have acceptance, respectful, trusting and have demeanor.

2. Student advisors should educate the students on their obligation to the counselling process through being honest, open, motivational and avoiding assumptions about the counsellor, among others as these are important to an effective counselling outcome on student learning motivation.

3. The counsellor should improve on areas rated as poor particularly in communication and counselling technique selection so that he becomes effective in learning motivation counselling.

4. The counsellor should receive personal counselling to equip him with experience knowledge to effectively provide counselling on learning motivation.

5. Programme Coordinators to whom some students were referred to lack counselling knowledge thus need to be trained in counselling if they are to be of any help on students learning motivation.

6. The number of Student Counsellors/Advisors should be increased significantly so that the counsellors can cope because some of the weaknesses of the counselling system were partly due to the fact that the student counsellor was under pressure from the huge numbers needing assistance.

7. For courses with less enrolment, academic support can be provided through other means rather than counselling sessions, like telephone, letters, e-mail, mobiles, formation of study circles etc.

8. Local advertisements can be made to attract the best talent in the town/village providing attractive and timely remuneration. A database of counsellors, course-wise for every course at each study centre can also be maintained (Avani Tribedi \& Kalpana Gupte, 2010).

9. Adequate advance information about counselling schedules to the learners and alternative arrangement in case of unforeseen departure from schedule can be provided. Review and renew of all appointments of counsellors, systematically and regularly to weed out unsuitable persons and allow for accommodating new prospective counsellors can also be done (Avani Tribedi \& Kalpana Gupte, 2010).

10. Study centres may be asked to send attendance copy of the counselling classes on same day after completion of conselling classes by e-mail of the concerned RC so that the appraisal of the learners can be collected from individual learner on telephone and measure can be taken to improve the quality of counselling classes by concerned RC.

11. The number of Student Counsellors/Advisors should be increased significantly so that the counsellors should not work under pressure from the huge number of learners needing assistance. 
12. To avoid the cancelation of counselling classes due to absence of counsellor, more number of counsellors should be empanelled for each course.

13. The counsellors should improve his/her communication skills and counselling techniques for effective and motivational counselling.

14. Web based video camera can be used for online monitoring of counseling services conducted at study centres.

\section{Discussion \&Conclusion:-}

In this article, an attempt has been made to study the details of counselling services provided by IGNOU. One of the crucial elements in distance education is the strength of its student support services. The above discussion leads us to conclude that:

1. The most employed method of counselling on learning motivation at the IGNOU is the face to face counselling, group counselling and at times telephone counselling and letters to a minimum extent.

2. At present, the learners prefer face-to-face counselling. However, they have shown a strong willingness to adopt ICT enabled counselling modes as well, such as through mobiles, website, multimedia CDs, email etc., which are essentially interactive in nature. The difficult topics should be discussed on a priority basis during counselling sessions. The Online cunselling service system should be developed for the learner community, along with other electronic media services

3. A strong family support, honest, voluntary, openness, resistance, motivation, assumptions about the counsellor and acceptance of responsibility are some of the student variables that are important to an effective counselling outcome.

4. Inadequate numbers of student Counsellors/Advisors is partly to blame for the ineffectiveness of the process of counselling students on learning motivation.

5. In order to improve academic counselling services of IGNOU, regular orientation and training programmes and follow up feedback mechanism are necessary for academic counsellors so that the academic counsellors understand and perform the roles expected of them with full satisfaction. Likewise, induction of learners into the distance learning process can prove to be very useful and serious attention must be paid to this aspect.

6. Appropriate monitoring mechanism can also be developed and designed by the Schools, the Regional Centres and the Regional Services Division with a view to seek proper feedback from the students, the analysis of which would prove to be useful for improvement in the counselling services.

7. Effective solutions should be developed for facilitating the learners' asynchronous learning through ICT tools, such as mobile, websites, multimedia CDs, email, etc. Emphasis should be on maximum use of EDUSAT and the Satellite Interactive Terminals, which support 2 way audio / video mechanisms and Voice over Internet Phone (VoIP), to provide the distance learners a virtual classroom that gives the look and feel of a real classroom.

Open Universities must respond to a student as soon as possible. A friendly, response to the learner's difficulties can generate a good spirit and confidence to achieve the goal. The counsellor's responsibility is to assist the one in trouble whether that difficulty stems from physical, mental, social or emotional causes. A counsellor must be familiar with the aims and subject-matter of each course. He/she must take the initiative in establishing a one-to-one relationship which can inspire a student to complete a difficult course and eventually achieve a career goal. Proper counselling should infuse confidence in the minds of distance learners to undergo self-study without any hurdle. It is pleasant to note that the IGNOU has been recognized by various international organizations for its services throughout the world. However, more efforts would further improve the counselling services of IGNOU.

\section{References:-}

1. Matthews, Diane (1999): The Origins of Distance Education. T.H.E. Journal, 27(2): 56-66.

2. P. Satyanarayana \& C. Sesharatnam (2000): Distance Education What? Why? How?. Publication of Booklinks Corporation, Hyderabad, India.

3. Indira Gandhi National University Profile, New Delhi (2017).

4. STRIDE, IGNOU (2012): Learner support systems and services.MDE-413: Block-3.

5. S. Kishore (2014): Academic Counselling in ODL. Turkish Online Journal of Distance Education,

6. 15(2): $98-107$

7. Distance Education Council (2009): Handbook, IGNOU, New Delhi.

8. Avani Trivedi \& Kalpana Gupte (2010): Quality Issues for Counselling in Open and Distance Learning in India. Asian Journal of Distance Education, 8(2): 50-58. 